\title{
УЧЕТ ОСОБЕННОСТЕЙ РЕЛЬЕФА В ЭКОЛОГИЧЕСКОМ МОНИТОРИНГЕ
}

\section{Григорий Владимирович Толкачев}

Сибирский государственный университет геосистем и технологий, 630108, Россия, г. Новосибирск, ул. Плахотного, 10, обучающийся, тел. (913)457-47-62, e-mail: tolkachevgrigir@mail.ru

В статье рассматриваются подходы к анализу рельефа как основы пространственного распространения различных видов загрязнения, влияющих на формирование экологической обстановки городских территорий. Выполнен анализ размещения постов наблюдательной государственной сети по положению в рельефе.

Ключевые слова: мониторинг городских земель, цифровая модель рельефа, морфометрия, количественные характеристики рельефа

\section{CONSIDERATION OF RELIEF FEATURES IN ENVIRONMENTAL MONITORING}

\section{Grigory $V$. Tolkachev}

Siberian State University of Geosystems and Technologies, 10, Plakhotnogo St., Novosibirsk, 630108, Russia, Student, phone: (913)457-47-62, e-mail: tolkachevgrigir@mail.ru

The article discusses approaches to the analysis of relief as the basis for the spatial distribution of various types of pollution that affect the formation of the ecological situation in urban areas. The analysis of the placement of posts of the state observation network by their position in the relief is carried out.

Keywords: monitoring the urban lands, digital elevation model, morphometric, quantitative topographic attributes

\section{Введение}

Развитие территорий города прежде всего отражается на увеличении антропогенной нагрузки на окружающую среду, что впоследствии требует повышение объективности результатов экологического мониторинга. Целый ряд как природных, так и факторов антропогенного происхождения влияет на формирование неблагоприятной экологической обстановки городской среды. К ним относятся особенности сложившейся инфраструктуры городской территории (расположение объектов энергетики и промышленности), характер застройки и метеоусловия. Повсеместное распространение в городских условиях имеют процессы переноса загрязняющих веществ, их аккумуляция, впоследствии отражающиеся на всех землях. Поэтому актуальным является исследование рельефа, как одного из природных факторов, влияющего на процессы переноса загрязняющих веществ, следовательно, требующего учета при организации мониторинга.

\section{Методы и материаль}

Используемая на данный момент система экологического мониторинга опирается на получение сведений о концентрации загрязняющих веществ в точках размещения стационарных постов, или дополнительных точках отбора проб. Это 
обеспечивает фиксацию характера выбросов источника загрязняющих веществ в окружающую среду, но не позволяет отслеживать их распространение по площади и интенсивности. Это связано с тем, что на характер распространения загрязнений влияют природные условия локального происхождения. К примеру, сочетание определенных метеорологических факторов может способствовать повышению уровня загрязнения воздуха за счет стока атмосферных осадков по склону, инфильтрации в грунты, накопления в замкнутых понижениях рельефа и др. [1]. В целом особенности рельефа оказывают существенное влияние на формирования зон загрязнения.

Следовательно, совершенствовать подходы к проведению мониторинга городских земель целесообразно на основе учета характерных особенностей и свойств территории. Среди них значимыми являются степень застроенности территории и морфология застройки, функциональное использование территории, которое влияет на наличие источников загрязнения, а также морфометрические особенности рельефа, способствующие формированию потоковых структур, определяющих распространение загрязнений. Специфика взаимодействия между природными и антропогенными объектами окружающей среды определяется характеристиками рельефа. Такие показатели, как углы наклона и экспозиция склонов, влияют на распределение влаги и солнечной энергии по территории, т. е. определяют терморежим склонов. Горизонтальная и вертикальная кривизна описывают механизмы аккумуляции загрязняющих веществ, следовательно можно прогнозировать распределение загрязняющих веществ, пути их миграции.

\section{Результаты и обсужндение}

Детальный анализ особенностей рельефа г. Новосибирска выполнен в работе [3]. Расширенный морфометрический анализ позволил получить характеристики рельефа, определяющие скорость и интенсивность переноса загрязняющих веществ, а также выявить зоны транзита и аккумуляции.

Полученные сведения послужили основой для анализа существующей системы мониторинга и разработки рекомендаций по совершенствованию мониторинга.

На территории города Новосибирск создана наблюдательная государственная сеть, в состав которой входит 10 стационарных постов, предназначенных, для обеспечения непрерывной регистрации содержания загрязняющих веществ или регулярного отбора проб воздуха для последующего анализа [6].

Анализ их пространственного расположения с учетом количественных характеристик рельефа (рисунок).

Оценивалось их расположение относительно зон выделенных на основе морфометрического анализа рельефа. Рассматривались зоны депрессий, то есть в которых потенциально могут накапливаться стоки, зоны дисперсий, то есть зоны рассеяния и зоны транзита вещества. Выявлено, что 3 поста размещены в дисперсивной зоне ( посты № 24, 25, 26), 3 - в транзитной зоне (посты №1,18,21), 4 в депрессивной зоне (посты № 19, 47, 49, 54). Оценивая рациональность их размещения, можно сделать предположение, что посты, расположенные вблизи 
автомагистралей, позволяют получать достаточно объективную информацию о загрязнении атмосферного воздуха. Посты, расположенные в жилых районах, находятся в зонах рассеяния загрязняющих веществ, поэтому определяемые концентрации загрязняющих веществ могут показать значения ниже фактических.

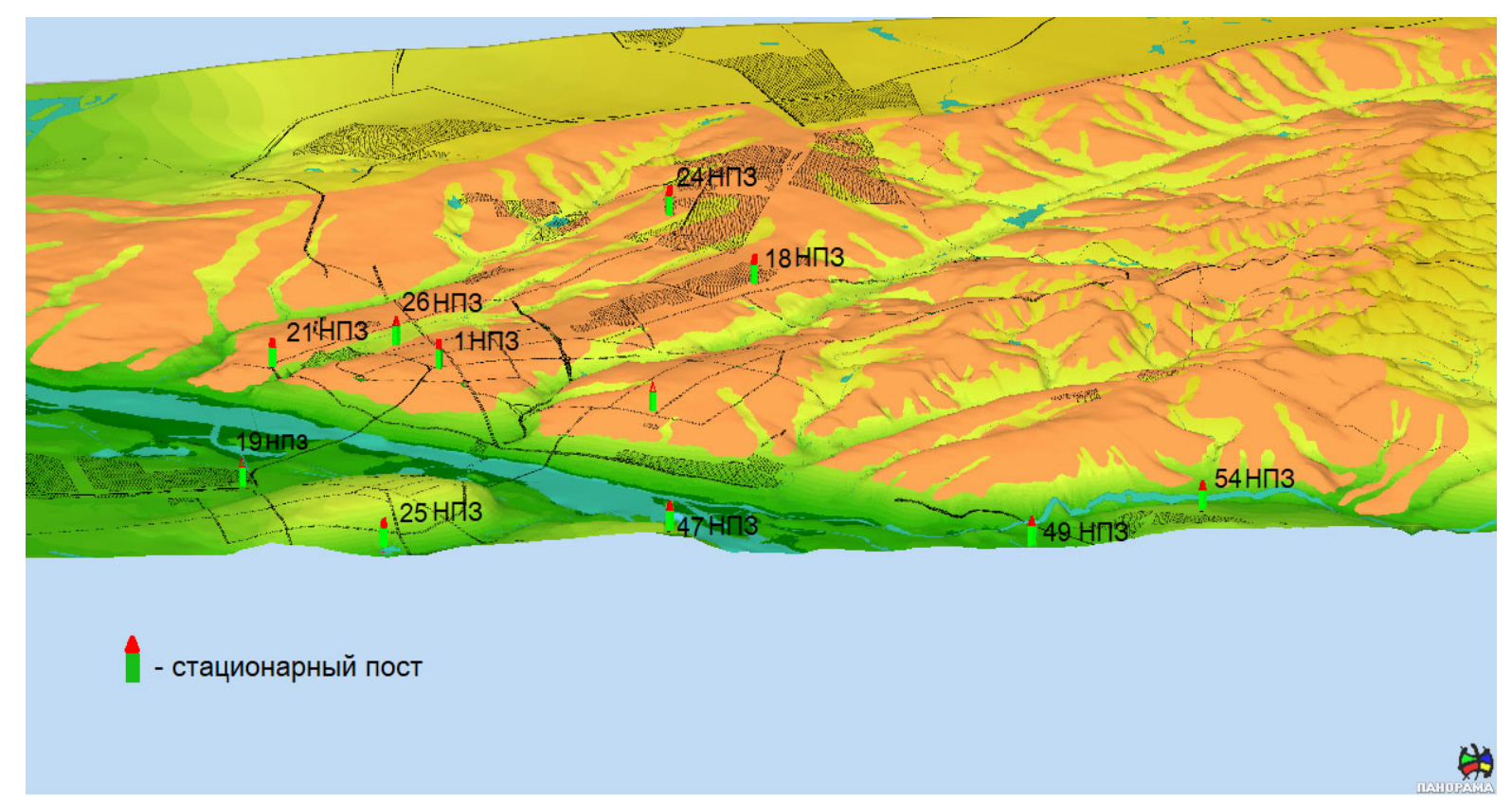

Расположение стационарных постов города Новосибирска на ЦМР

В целом, можно отметить, что количество существующих на данный момент постов недостаточно, особенно это касается промышленных зон, являющихся одними из самых опасных и требующих постоянного контроля.

Учет особенностей рельефа при экологическом мониторинге требует дальнейших исследований, включающих комплексный анализ различных факторов.

\section{Заключение}

Выделение потенциально неблагоприятных зон с экологической точки зрения на основе результатов морфометрического анализа рельефа, позволяет дополнить структуру информационного обеспечения дополнительными точками отбора проб в наиболее неблагоприятных местах, что будет способствовать повышению объективности экологического мониторинга.

Количественные характеристики рельефа позволяют охарактеризовать специфику распространения загрязняющих веществ разными средами, включающими воздушные массы, поверхностные и подземные воды. Интеграция этих сведений с другой тематической информацией обеспечит всесторонний анализ городской территории для выявления и прогнозирования участков загрязнения. Что позволит принимать меры по распространению загрязнений от разных источников. 
Таким образом, системный подход к изучению городской территории обеспечивается анализом взаимосвязей и взаимовлияния различных компонентов окружающей среды, при этом одним из ведущих является рельеф. Оптимально использовать цифровую модель рельефа с выделенными потоковыми структурами. Такая информация позволит повысит объективность экологической оценки исследуемой территории, и оптимизировать размещение объектов производственной инфраструктуры.

\section{БИБЛИОГРАФИЧЕСКИЙ СПИСОК}

1. Степановских, А .С. Экология [Текст]: учебник для вузов / А. С. Степановских. - М.: ЮНИТИ-ДАНА, 2001. - 703 с.

2. Хромых, В. В. Цифровые модели рельефа [Текст]: учеб. пособие / В. В. Хромых, О. В. Хромых. - Томск: ТМЛ-Пресс, 2007. - 177 с.

3. 3. Панов Д.В. Совершенствование информационного обеспечения мониторинга городских земель на основе учета особенностей рельефа Автореферат диссертации на соискание ученой степени кандидата технических наук, 2014, 24c.

4. Трубина, Л. К. Совершенствование мониторинга городских земель на основе учета особенностей рельефа [Текст] / Л. К. Трубина, Д. В. Панов // Изв. вузов. Геодезия и аэрофотосъемка. - 2014. - № 5/с. - С. 157-161.

5. Трубина, Л. К. Некоторые аспекты учета экологической составляющей при мониторинге земель городских территорий [Текст] / Л. К. Трубина, Д. В. Панов // Изв. Вузов. Геодезия и аэрофотосъемка. -2012. - № 2/1 - С. 121-123.

6. Государственный доклад о состоянии и об охране окружающей среды Новосибирской области в 2019 году- Новосибирск 2020. С, 10-15.

(C) Г. В. Толкачев, 2021 